\title{
Temporal Course of Motor Recovery After Brown-Sequard Spinal Cord Injuries
}

James W. Little, M.D. Ph.D. ${ }^{1,2}$ and Eugen Halar, M.D. ${ }^{2}$

${ }^{1}$ Medical Research Service. ${ }^{2}$ Rehabilitation Medicine Service Seattle V.A. Medical Center, and University of Washington, U.S.A.

\begin{abstract}
Summary
Recovery of voluntary motor function after incomplete spinal cord injuries is attributed to a variety of physiological mechanisms, such as resolution of conduction block in injured axons, and neuroplasticity mechanisms in spared axons. To better understand these recovery mechanisms, we have examined motor recovery in one type of incomplete cord injury, the Brown-Sequard Syndrome. This syndrome is observed in patients with unilateral injury of the spinal cord and is manifested as asymmetric weakness and pain/temperature sensory loss contralateral to the weakest extremity. We have followed the course of motor recovery in two patients and reviewed the literature in an additional 59. Common features of this motor recovery include: 1) recovery of ipsilateral proximal extensor muscles before ipsilateral distal flexors, 2) recovery of any weakness in the extremity with pain/temperature sensory loss before the opposite extremity, and 3) recovery of voluntary motor strength and a functional gait by 1 to 6 months. We discuss these observations with respect to three hypotheses to explain motor recovery and suggest that neuroplasticity mechanisms functioning in spared descending axons may mediate much of the observed recovery after Brown-Sequard cord lesions.
\end{abstract}

Key words: Spinal cord injury; Brown-Sequard Syndrome; Motor recovery.

\section{Introduction}

As many as 17 to 41 per cent of spinal cord injuries are reported to be motor incomplete, such that significant motor recovery occurs (Bosch et al., 1971; Bedbrook, 1979; Young and Northrup, 1979). Commonly these patients are totally paralysed initially but gradually regain voluntary motor strength and functional ambulation. Brown-Sequard Syndrome is one category of incomplete cord injury which undergoes such remarkable motor recovery (Taylor and 
Gleave, 1957; Bosch et al., 1971). Such patients manifest primarily unilateral motor paralysis and contralateral loss of pain and temperature sensation. BrownSequard (1860) was the first to relate these asymmetric clinical deficits to unilateral cord injury by noting similar asymmetric motor and sensory deficits in animals subjected to spinal cord hemisection.

In this paper, two patients with Brown-Sequard syndrome are described and the literature on motor recovery in this syndrome is reviewed. Various mechanisms postulated to explain this recovery are discussed with respect to the temporal patterns of recovery observed.

Only lower extremity recovery is addressed. Cases described met the following criteria to include only Brown-Sequard type injuries and to exclude any weakness caused by lower motoneuron injury: 1) cord injury above the T12 level, 2) asymmetric lower extremity weakness, 3 ) asymmetric sensory loss, with pinprick and temperature loss contralateral to the motor loss.

\section{Case descriptions}

\section{Case 1}

J.P. is a 42 -year-old male who suffered immediate left leg paralysis after a knife wound penetrating between T6 and T7 spinous processes. Thirteen days after injury a laminectomy was performed at the site of injury; findings included a horizontal laceration of the dura and left spinal cord, involving the left dorsal column and left lateral funiculus, though the complete lateral and ventral extent of the injury was not determined.

Sensory findings included decreased pin-prick and temperature sensation on the right trunk below the costal margin and right lower extremity.

Paralysis of the left lower extremity but preserved strength on the right was noted the day of injury (Fig. 1). Examination on day 16 revealed full strength

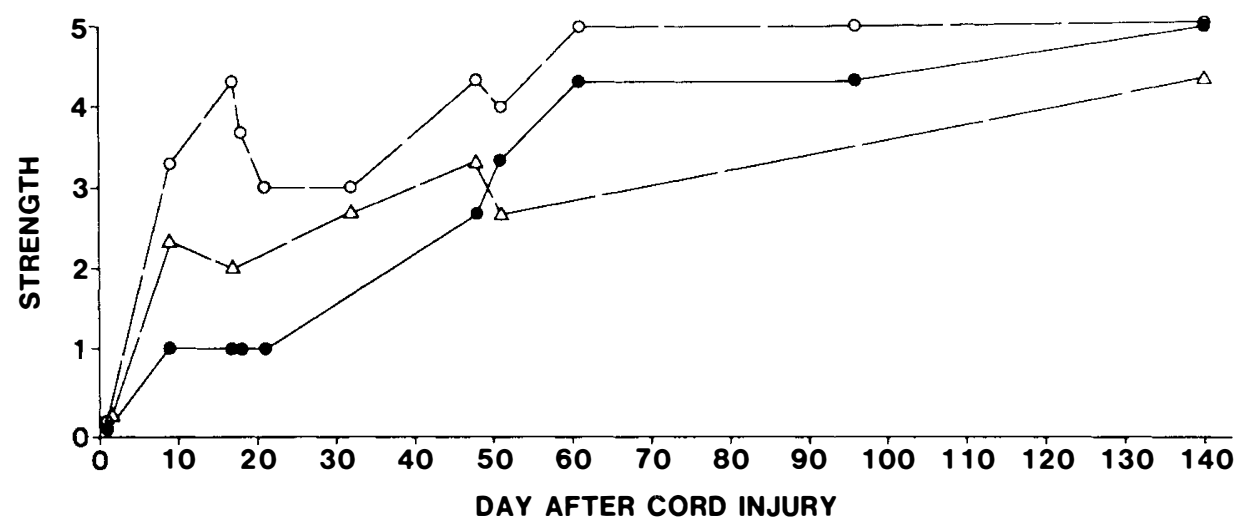

Figure 1. Ipsilateral Motor Recovery after Brown-Sequard Syndrome. Grading of muscle strength for knee extensors (open circles), hip flexors (open triangles), and ankle dorsiflexors (solid circles) ipsilateral to a Brown-Sequard cord injury. Note ipsilateral knee extensors recover significantly sooner than ipsilateral ankle dorsiflexors. Strength is graded 0 to $5: 1=$ trace movement, 2 = some movement but not anti-gravity strength, $3=$ anti-gravity strength, $4=$ antigravity strength plus some resistance, $5=$ full strength. Patient J.P. 
in the right lower extremity. In the left, muscle strength was grade 4 knee extension, grade 2 hip flexion, and grade 1 ankle dorsiflexion. By 3 months post-injury, hip flexion and ankle dorsiflexion had gradually attained grade 4 strength.

Functionally, J.P. progressed from ambulating 20 feet in parallel bars by 3 weeks, to walking independently up to 15 feet with a walker by 1 month, to ambulating with axillary crutches but with persisting left foot drop by 7 weeks, to walking without aids and minimal foot drop by six months.

\section{Case 2}

G.W. is a 19-year-old male who suffered immediate onset quadriplegia after a motor vehicle accident. Cervical spine $X$-rays revealed $4 \mathrm{~mm}$ anterior displacement of $\mathrm{C} 4$ on $\mathrm{C} 5$; computed axial tomography demonstrated several nondisplaced fractures of the left lateral mass of $\mathrm{C} 4$. The dislocation was reduced on a Stryker frame with tongs and 17 pounds traction. Posterior wiring of C4-5 with a bone fusion was performed 9 days post-injury.

Sensory findings included absent pin-prick and temperature sensation in the right trunk and right lower extremity.

Initially both lower extremities were flaccid until trace knee extension and toe flexion developed on the right between 6 and 18 hours post-injury (Fig. 2). Strength rapidly returned thereafter in the right leg with grade 2 to 4 strength returning to all muscles groups by day 4 . Voluntary movements in the left leg were first noted between days 2 and 4 in ankle plantarflexors. By day 22, left knee extension and ankle plantarflexion were grade 3 though hip flexion and ankle dorsiflexion were only grade 1 (Fig. 3). Yet in spite of this minimal early recovery, by 3 months left hip flexion and ankle dorsiflexion had achieved grade 4 voluntary strength.



Figure 2. Ipsilateral and Contralateral Motor Recovery after Brown-Sequard Syndrome. Grading of muscle strength for knee extensors (squares) and ankle dorsiflexors (circles), ipsilateral (open) and contralateral (solid) to a Brown-Sequard cord injury. Note the contralateral extremity recovers before the ipsilateral. Also, the ipsilateral knee extensors recover notably sooner than ankle dorsiflexors; however, contralaterally, the ankle dorsiflexors recover as soon or sooner than the knee extensors. Strength grading as in Figure 1. Patient G.W. 


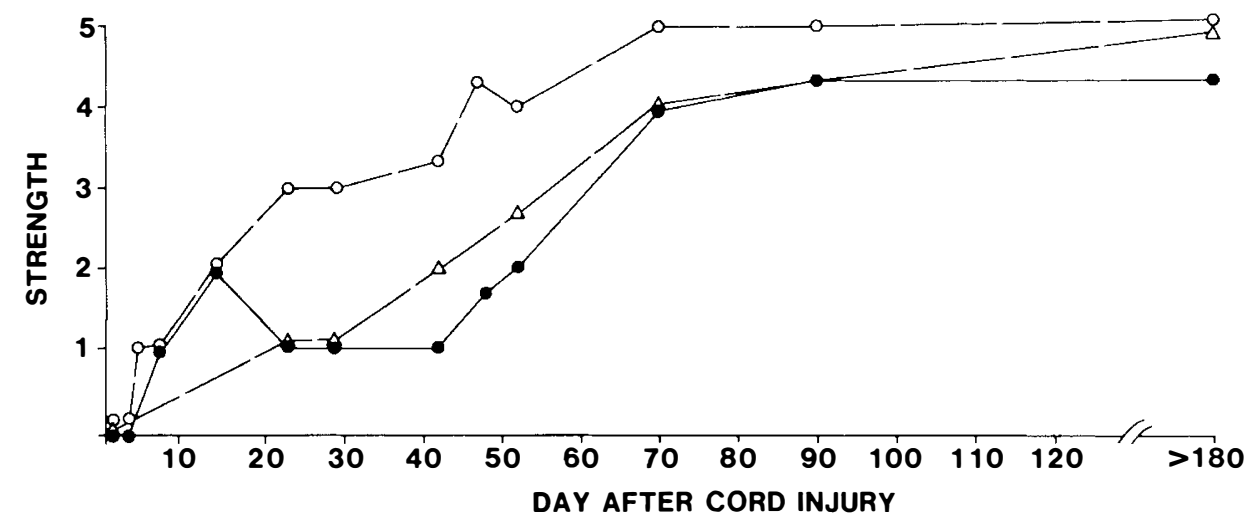

Figure 3. Ipsilateral Motor Recovery after Brown-Sequard Syndrome. Grading of muscle strength for knee extensors (open circles), hip flexors (open triangles), and ankle dorsiflexors (solid circles) ipsilateral to a Brown-Sequard cord injury. Note ipsilateral knee extensors recover significantly sooner than ipsilateral ankle dorsiflexors. Strength grading as in Figure 1. Patient G.W.

Functionally, G.W. was performing standing pivot transfers with moderate balance assistance by 1 month. At 7 weeks, he was ambulating up to 50 feet with a right platform crutch and left ankle-foot orthosis, though he still required contact guarding for balance assistance. By 10 weeks, he was ambulating independently up to 400 feet without crutch or orthosis though a left foot slap persisted at left heel strike. At six months post-injury, the left foot slap had resolved and his ambulation endurance without aids was several miles.

\section{Discussion}

Significant motor recovery following Brown-Sequard spinal cord injuries is well-documented (Mann, 1896; Taylor and Gleave, 1957). We have identified 59 previously-described cases which meet our above-mentioned criteria for Brown-Sequard Syndrome (Table 1). Review of this literature suggests that motor recovery after Brown-Sequard Syndrome has characteristic temporal features.

First, in all 59 cases, significant voluntary strength and functional ambulation recovered in the lower extremities, even though there was usually complete paralysis initially. Peacock et al. (1977) state, '... it is hard to believe that ipsilateral motor recovery would be as good as it usually is, if the cord were actually hemisected. If the cord is merely contused or vascular damage is temporary, recovery is understandable.' However, one rarely finds cases of unilateral persisting paralysis, even among patients with anatomically-confirmed section of all or most ipsilateral descending input (Case J.P.; Nathan and Smith, 1973). Thus, motor recovery occurs even though most or all ipsilateral descending input has been sectioned.

Second, motor recovery proceeds over a period of one to 6 months, though it often begins within 24 to 48 hours following the cord injury (Case G.W.; Feldman, 1933; Nathan and Smith, 1973). It seems unlikely that the mechanisms 
Table 1 Review of Brown-Sequard Syndrome

\begin{tabular}{|c|c|c|c|c|c|}
\hline \multirow[b]{2}{*}{ Study } & \multicolumn{2}{|c|}{ Nature of Cord Injury } & \multicolumn{2}{|c|}{ Level of Injury } & \multirow{2}{*}{$\begin{array}{c}\text { Functional } \\
\text { Motor Recovery }\end{array}$} \\
\hline & Open & Closed & Above T3 & Below T3 & \\
\hline Bohlam (1979) & & 6 & 6 & & 4 (2 lost to follow-up) \\
\hline Bosch et al. (1971) & & 5 & 5 & & 5 \\
\hline Brown-Sequard (1869) & 3 & & 3 & & 3 \\
\hline Cushing (1898) & 2 & & 1 & 1 & 1 (1 lost to follow-up) \\
\hline Eve (1857) & 1 & & 1 & & 1 \\
\hline Feldman (1933) & 3 & & 1 & 2 & 3 \\
\hline Guillain, Garcin (1931) & 3 & & & 3 & 3 \\
\hline Guillain, Corre (1950) & 1 & & 1 & & 1 \\
\hline Preston (1896) & 1 & & 1 & & 1 \\
\hline Rand, Patterson (1929) & 2 & & 1 & 1 & 2 \\
\hline St John, Rand (1953) & 5 & & 3 & 2 & 4 (1 lost to follow-up) \\
\hline Taylor, Gleave (1957) & 16 & 11 & 18 & 9 & 27 \\
\hline Total & 37 & 22 & 41 & 18 & 55 \\
\hline Percent & 63 & 37 & 69 & 31 & 100 \\
\hline
\end{tabular}

mediating rapid early recovery during the first several days are the same as those that mediate prolonged late recovery for several months after cord injury. Presumably multiple recovery mechanisms are responsible.

Third, in the ipsilateral lower extremity, knee extensors recover notably sooner than ankle dorsiflexors (Cases J.P., G.W.; Mann, 1896; Cushing, 1898; Taylor and Gleave, 1957). Some have suggested ipsilateral recovery proceeds in an extensor-to-flexor order (Mann, 1896; Cushing, 1898). Our observations in the present two cases suggest that both an extensor-to-flexor and a proximal-to-distal recovery may occur, such that strength returns to ipsilateral knee extensors much before ankle dorsiflexors, and ankle plantarflexors and hip flexors have an intermediate rate of recovery (Figs. 1, 2, 3).

Fourth, contralateral motor recovery often appears much earlier than in the ipsilateral lower extremity in patients with initial bilateral paralysis (Case G.W.; Holmes, 1915; Guillain and Garcin, 1931; Taylor and Gleave, 1957). In their review, Taylor and Gleave (1957) stated: 'Motor recovery was rapid on the contralateral side ... [recovery] was often complete within a week ... but was much slower on the ipsilateral side, where it remained incomplete, ... but with some retention of voluntary control.' In contrast to ipsilaterally, contralateral distal flexors recover as soon or sooner than contralateral proximal extensors (Case G.W.; Feldman, 1933). This temporal pattern of motor recovery has been observed in an animal model of Brown-Sequard Syndrome as well (Little, 1976).

Recovery of voluntary motor function caudal to a Brown-Sequard cord injury has been attributed to a variety of mechanisms. One proposal is that conduction block in descending motor pathways resolves at the site of injury; this restoration of conduction may represent resolution of oedema, haematomyelia, ischaemia, focal demyelination or direct pressure (Taylor and Gleave, 1957; Bohlman, 1979). A second hypothesis is that neuronal plasticity mechanisms such as denervation supersensitivity (Cannon and Haimovici, 1939; Stavraky, 1961), and collateral sprouting (Murray and Goldberger, 1974; Little, 1976) operate 
in spared descending pathways; this allows spared axons to assume the motor functions previously mediated by descending axons which degenerate as a result of the cord injury (Turner, 1891; Nathan and Smith, 1973; Little, 1976). A third possibility mentioned but generally discounted is regeneration of axons interrupted by the injury (Turner, 1891; Feldman, 1933).

Recent evidence from human and animal studies suggests that spared descending motor axons, coursing in the contralateral cord, may mediate much of the motor recovery in Brown-Sequard Syndrome.

Nathan and Smith (1973) describe motor recovery in patients who underwent unilateral section of the ventral and lateral funiculi of the cord to relieve intractable pain of terminal malignancies. As with traumatic injuries, there was initial complete paralysis of the ipsilateral lower extremity, with gradual recovery of voluntary motor strength and functional ambulation over several months. A subsequent contralateral cord hemisection, performed to eliminate recurrent pain, abolished the initial recovery and both lower extremities became paralysed. Similar observations have been made in animal models of Brown-Sequard Syndrome; section of contralateral spinal tracts (Turner, 1891; Jane et al., 1964) or lumbar commissural fibers (Little, 1976) abolishes motor recovery in the extremity ipsilateral to the cord hemisection. Thus, in animals, as in humans, this recovery was likely mediated by spared descending pathways coursing in the contralateral cord.

The differential rates of motor recovery for contralateral versus ipsilateral muscles and for ipsilateral proximal extensors versus distal flexors has been previously attributed to varying duration of conduction block, whether due to edema, haemorrhage, ischemia, demyelination, or mechanical pressure (Taylor and Gleave, 1957). A single factor causing conduction block would not explain the strikingly different rates of motor recovery; its resolution would not explain why conduction should be largely restored in descending axons mediating knee extension within several days, while in neighbouring axons, mediating hip flexion and ankle dorsiflexion, three months are required to restore conduction. Even if multiple factors cause conduction block and resolve at different rates, it is not clear why ipsilateral proximal extensors should consistently recover sooner than ipsilateral distal flexors.

Alternatively, differential rates of motor recovery may be explained in terms of the distribution of spared contralateral pathways. Kuypers and colleagues (1981) have shown in non-human primates that contralateral descending pathways are preferentially distributed to ipsilateral proximal extensors and minimally distributed to distal flexors. Thus, if rate of motor recovery depends on the number of spared inputs, e.g. as mediated by collateral sprouting of those inputs, then ipsilateral proximal extensors might recover sooner than ipsilateral distal flexors. Likewise, contralateral muscles would recover sooner than ipsilateral muscles because of greater spared input. A largely unilateral cord injury, as occurs in Brown-Sequard Syndrome, possibly with some extension across the midline to involve some of the contralateral ventral funiculus, would more severely reduce input to contralateral proximal extensors than to contralateral distal flexors. Thus, one would expect contralateral recovery of distal flexor strength prior to proximal extensor strength, as has been observed in humans (Case G.W.; Feldman, 1933) and in cord-hemisected animals (Little, 1976). 
The mechanism of axon regeneration across a cord injury would seemingly not explain the temporal pattern of motor recovery observed after BrownSequard lesions. One would expect patients with cord injuries at low thoracic levels to regain motor function in the lower extremities much before such injuries at cervical levels. However, the temporal course of motor recovery is similar whether the Brown-Sequard lesion is in the cervical or thoracic cord. Axon regeneration does not readily explain the temporal course of motor recovery observed after Brown-Sequard Syndrome.

These limited observations on motor recovery in two patients with BrownSequard syndrome are in general agreement with previous literature and suggest there are characteristic temporal patterns to the recovery. Additional studies of this motor recovery are warranted, particularly with respect to the possible role of neuroplasticity mechanisms functioning in contralateral pathways. The underlying recovery mechanisms allow a much reduced complement of descending motor input to mediate functional motor recovery.

\section{Acknowledgment}

This work was supported by Rehabilitation Research and Development Service of the Veterans Administration.

\section{Résumé}

Le rétablissement des fonctions motrices intentionnelles après une lésion partielle de la moëlle épinierè est du á un échantillon de facteurs physiologiques, tel que l'élimination des transmissions des impulsions nerveuses dans le cas d'axone lésés et des mécanismes neuroplastiques dans le cas d'axones limités. Afin de mieux comprendre ces mécanismes de rétablissement, nous avons étudié le rétablissement moteur d'un type de lésion incomplète de la moëlle, le syndrome de BrownSequard. Ce syndrome s'observe chet les patients qui ont une lésion unilatérale de la moëlle épinierè. Nous avons étudié l'evolution d'un rétablissement moteur chez deux patients et établi une critique littéraire chez 59 d'autre patients. Les caractéristiques les plus fréquentes de ce rétablissement moteur recouvrent: 1) Le rétablissement ipsilatérale des muscles extenseurs proximal et ce avant l'ipsilatéral des fléchisseux périphériques, 2) le rétablissement de toutes faibleses á l'extrémité qui avait une anésthesié sensonielle thermique et ce avant l'extrémité opposeé, 3) le rétablissement de la force intentionnelle motrice et une fonction motrice dans l'espace d'un ou six mois. Nous examinons ces observations en tenant compte de ces trois hypothesès pour expliques le rétablissement moteur et nous suggérons que les mécanismes neuroplastiques fonctionnant en limitant les axones puissent grandement servi d'intermédiare au rétablissement observé après les lésions de la moëlle épinierè de Brown-Sequard.

\section{Zusammenfassung}

Die Wiederherstellung von voluntärer motorischer Funktion nach teilweiser Rückenmarkverletzung wird auf verschiedene physiologische Mechanismen zurückgeführt, wie zum Beispeil Resolution des Konductions Blocks in verletzten Axonen and die Ersetzung der Funktion von verschonten Axonen. Um diese Genesungsmechanismen besser zu verstehen, untersuchten wir die motorische Genesung in einer bestimmten Art von teilweiser Rückenmarkverletzung, nämlich das BrownSequardische Syndrom. Dieses Syndrom findet man bei Patienten mit unilateraler Verletzung des Rückenmarks. Wir haben den Verlauf von motorischer Wiederherstellung in zwei Patienten verfolgt und die Fachliteratur von 59 weiteren Fällen hinzugezogen. Gemeinsame Merkmale dieser motorischen Genesung schliessen Folgendes mit ein: 1) Wiederherstellung der ipsilateralen proximalen Streckmuskeln vor den ipsilateralen distalen Flexoren, 2) Genesung jeglicher Schwäche in der Extremität mit dem Verlust der Schmerz- und Temperaturempfindung vor der gegenüberliegenden Extremität, und 3) Wiederherstellung der voluntären motorischen Stärke und ein funktioneller Gang in ein- bis sechs Monaten. Wir haben diese Punkte angeführt hinsichtlich von drei Hypothesen um 
motorische Genesung zu erklären and wir schlagen vor, dass das Ersetzen der Funktion durch verschonte motorische Axonen, in der beobachteten Genesung nach einer Brown-Sequardischen Rückenmarkverletzung, eine bedeutende Rolle spielen.

\section{References}

BEDBROOK GM 1979 Spinal Injuries with tetraplegia and parapiegia. Journal of Bone and Joint Surgery 61-B:267-284.

BoHLman HH 1979 Acute fractures and dislocations of the cervical spine. Journal of Bone and Joint Surgery 61-A:1119-1141.

Bosch A, STAUFFER ES, NiCKel VL 1971 Incomplete traumatic quadriplegia. Journal of American Medical Association 216:473-478.

BRown-SEQUARD CE 1860 Course of Lectures on the Physiology and Pathology of the Central Nervous System. Collins, Philadelphia.

BROWN-SEQUARD CE 1896 Lectures on the physiology and pathology of the nervous system.

Lancet 1:1-6, 65-69, 233-235, 401-404, 457-462.

CANNon WB, Haimovici H 1939 The sensitization of motoneurons by partial denervation. American Journal of Physiology 126:731-740.

Cushing HW 1898 Haematomyelia from gunshot wounds of the spine: a report of two cases, with recovery following symptoms of hemilesion of the cord. American Journal of Medical Science 115:654-683.

Eve PF 1857 A Collection of Remarkable Cases in Surgery, pp 104-105. J.B. Lippincott \& Co., Philadelphia.

FELdman P 1933 Knife wounds of the spinal cord. Sovet. Psikhonevrol. 2:33-51.

Guillain G, Garcin R 1931 Le syndrome de Brown-Sequard d'origine traumatique. Annales de Médecine 29:361-385.

Guillain G, Corre L 1950 Considerations sur un cas de syndrome de Brown-Séquard d'origine traumatique exceptionelle. Bulletin de l'Académie Nationale de Médecine 134:147-153.

Holmes G 1915 The Goulstonian lectures on spinal injuries of warfare. British Medical Journal 2:855-861.

JANE JA, EvANS JP, Fisher LM 1964 An investigation concerning the restitution of motor function following injury to the spinal cord. Journal of Neurosurgery 21:167-171.

KUYPERS HGJM 1981 Anatomy of the descending pathways. In: Brooks VB (ed) Handbook of Physiology, Section 1: The Nervous System, Volume II, Part 1. American Physiological Society, Bethesda.

Little JW 1976 Recovery of Function following Spinal Cord Lesions in Cats. PhD Dissertation, Univ of Chicago, Chicago.

MANN L 1896 Klinische und anatomische Beitrage zur Lehre von der spinalen Hemiplegie. Deut. Zeit. f. Nervenheilkunde 10:1-66.

MURRAY M, GolDBERGER ME 1974 Restitution of function and collateral sprouting in the cat spinal cord: the partially hemisected animal. Journal of Comparative Neurology 158: 19-36.

NATHAN PW, SMITH MC 1973 Effects of two unilateral cordotomies on the motility of the lower limbs. Brain 96:471-494.

PeAcock WJ, Shrosbree RD, Key AG 1977 A review of 450 stab wounds of the spinal cord. South African Medical Journal 51:961-964.

PRESTON CJ 1896 Brown-Sequard paralysis, with report of a case. Journal of Nervous and Mental Disease 21:645-651.

RAND CW, Patterson GH 1929 Stab wounds of the spinal cord. Surgery Gynecology and Obstetrics 48:652-661.

ST John JR, RAND CW 1953 Stab wounds of the spinal cord. Bull. Los Angeles Neurological Society 18:1-24.

Stavraky GW 1961 Supersensitivity following Lesions of the Nervous System. University of Toronto, Canada.

TAYloR RG, Gleave JRW 1957 Incomplete spinal cord injuries with Brown-Sequard phenomena. Journal of Bone and Joint Surgery 39-B:438-450.

TURNER WA 1891 On the hemisection of the spinal cord. Brain 14:496-522.

YOUNG JS, NoRThruP NE 1979 Statistical information pertaining to some of the most commonly asked questions about SCI. National Spinal Cord Injury Data Research Center, Phoenix, p. 28. 